This is the author's pre-print manuscript as submitted for refereeing and publication. The penultimate, refereed, publisher-formatted PDF may be available through the journal web site or your college and university library.

\title{
Why new mathematics teachers do or don't use practices emphasized in their credential program
}

Julie Gainsburg

\section{Manuscript Citation}

The following (APA) citation may be used to reference this manuscript:

Gainsburg, J. (2012). Why new mathematics teachers do or don't use practices emphasized in their credential program. Retrieved from http://scholarworks.csun.edu

\section{Published Version Information}

Citation: Gainsburg, J., (2012). Why new mathematics teachers do or don't use practices emphasized in their credential program. Journal of Mathematics Teacher Education, 15(2), 1-21.

Copyright: Copyright @ Springer

Digital Object Identifier (DOI): 10.1007/s10857-012-9208-1

This item was retrieved from CSUN ScholarWorks, the open-access, institutional repository of California State University, Northridge. http://scholarworks.csun.edu 


\section{Introduction}

A major research concern for teacher education is the impact of university teacherpreparation programs on $\mathrm{K}-12$ teaching practice. Conventional wisdom holds that this impact is low - that new teachers make limited use of university-promoted teaching methods - but more research is needed for an accurate assessment. Recent political pressures in the U.S. on credential programs to demonstrate their effectiveness add urgency to such research. Beyond the extent of impact on teaching practice, teacher educators want to understand the process that leads from learning an educational concept or method at the university to its eventual adoption in the K-12 classroom. Why are some practices taken up and not others? What can credential programs do to increase the odds that the practices they preach will become part of their graduates' teaching repertoires?

These questions are particularly salient in mathematics education, where the disjuncture between university-promoted practices and what teachers actually do may be greatest.

Mathematics-credential programs typically adhere to a constructivist philosophy (Clift \& Brady, 2005) and promote reform-oriented methods aligning with documents produced by the National Council of Teachers of Mathematics (NCTM, 1989, 2000). Yet, mathematics teaching in the U.S., by teachers at all levels of experience, remains largely traditional, characterized by direct instruction and individual student practice of procedures (Jacobs et al., 2006).

Proposed explanations for this disjuncture invoke different areas of the teaching enterprise. Limitations in teacher knowledge have been blamed. Historically, teachers across subjects have struggled to translate the general theories they learn at the university into concrete teaching strategies that will work in their specific contexts. This struggle may be exacerbated in mathematics, where reform teaching is considered more difficult than traditional. Teacher beliefs have also been blamed. Having served a 16-year "apprenticeship of observation” (Lortie, 1975) of traditional teaching as students themselves, many teachers have developed traditional conceptions about mathematics content, teaching, and learning that may cause them to resist reform ideas (Ball, 1990; NCTM, 1991). Finally, school, district, and broader educational cultures have been blamed for suppressing pedagogical innovation; thus, even teachers with the knowledge and desire to implement reform methods may be discouraged or blocked by environmental constraints. Knowing where the explanation for the university-practice disjuncture lay would inform credential programs about where to intensify their efforts-increasing mathematics teachers' knowledge and skills, changing teachers' beliefs, partnering with schools and districts to change their cultures, and/or "inoculating” new teachers against environmental pressures that inhibit reform teaching.

Despite the importance of understanding the (dis)connections between university and practice, research in this area has been limited (Clift \& Brady, 2005; Thompson, 1992). Most credential-program impact studies have examined changes in teachers' beliefs or attitudes, usually as the result of a single course and measured soon after the course ends (Clift \& Brady, 2005). The rarer studies that have explored program impact on actual teaching behavior tend to target student teaching - a transitional stage partly under the university umbrella. Few studies have followed teachers from the university into subsequent years of independent teaching to investigate whether and why they implement practices taught in their credential programs. 


\section{Background}

In the 2006-07 and 2008-09 school years, a team from California State University, Northridge conducted an observation and interview study of 19 teachers who had recently graduated from our mathematics-credential program, to learn:

- To what degree do recent graduates implement program-emphasized teaching practices in their classrooms?

- What factors support or constrain the implementation of these practices?

The team convened a focus group of program faculty to come to consensus on a set of research-based mathematics-teaching practices (henceforth, the Practices) that were emphasized in the program, were fair to expect a new teacher to demonstrate, and, for practical reasons, could be observed in a single lesson. Unsurprisingly, the Practices ultimately nominated were mainstays of reform mathematics (NCTM, 2000):

1) Teacher asks questions or poses tasks with a high level of cognitive demand;

2) Students given authority to judge the mathematical soundness of publicly presented solutions or methods;

3) Teacher connects (or poses tasks that prompt students to connect) the featured mathematics topic to another mathematics topic;

4) Teacher connects (or poses tasks that prompt students to connect) the featured mathematics topic to another academic topic;

5) Teacher connects (or poses tasks that prompt students to connect) the featured mathematics topic to a real-life situation;

6) Students allowed or encouraged to choose among solving methods or present alternative methods;

7) Teacher or students use technology, manipulatives, body movement, or other nonverbal support for a mathematics concept;

8) Specific attention paid to language (i.e., writing, reading, or speaking skills);

9) Teacher uses or encourages students to use multiple forms of representation for the same problem.

For each observed lesson taught by our graduates, the researcher rated each Practice as having played a significant, marginal, or no role in the lesson. The researcher also recorded the time spent in each of 11 predetermined teaching modes expected to cover all classroom activity. Observation data were complied to create a practice profile for the group. After each lesson, the researcher interviewed the teacher to explore the factors that supported and constrained her use of the Practices.

These observations confirmed the conventional wisdom: Our recent graduates use some program-emphasized Practices, but as a group they have not made them central to their teaching. Despite what we consider a strong reform orientation of our coursework, our typical graduate mainly employs traditional teaching modes. For most of the average lesson, the teacher presents 
content, students practice taught procedures, and the teacher gives behavioral directives or task instructions. The most frequently observed Practices were:

- Asking questions or posing tasks with high cognitive demand, significant in $37 \%$ of the lessons;

- Giving students the authority to judge the mathematical soundness of a solution or method, significant in $29 \%$ of the lessons.

No other Practice was significant in more than $15 \%$ of the lessons.

We had expected this low level of implementation of program-emphasized Practices, but we hoped the interview would reveal explanations for low (or high) implementation that could contribute to scholarship on this issue as well as inform our program. This article presents what we learned about the factors that influence our graduates' use of the Practices.

Education scholars have defined practice to encompass not just teaching actions and strategies but also what the teacher thinks, believes, and feels about them (Simon \& Tzur, 1999) and their environmental contexts and historical traditions (Grossman, Compton, et al., 2009). In sum, the concept of practice entwines action with perception, regularity, and context. It also begs the question of for whom an action is a practice. Arguably, a teaching strategy that a teacher uses only once, perhaps by coercion, is not a practice for her, though it may be one for the profession. In this article, I use the word practice because the actions targeted are part of the professional practice of (reform) mathematics teaching. What we observed, of course, were actions. We did not systematically measure how regularly each participant took them, although the interview inquired about the frequency of some actions. Observing 19 teachers offered a sense of how regular these actions were across the group-more germane to a study of programmatic impact. We avoided judgments about whether an individual's action should be considered a practice (e.g., due to frequency or personal commitment). Our understanding of beginning teachers suggested that many of their actions are being "tried out" and are not yet rooted in their identity or philosophy. We were equally interested in strategies the teachers tried occasionally, despite doubts about the strategy's efficacy (or their own), as we were in strategies they used routinely with comfort. The interview addressed the perceptive facets of practice: the participants' thoughts about the targeted actions, their motivations for using or avoiding them, and how these actions fit (or had to be modified for) their context. Combining observation and interview data, we aimed to characterize the practice of this group of recent graduates. This article describes the investigation of the perceptive aspect of these teachers' practice.

Studying a single program limits the generalizability of results, although the potential for generalization is enhanced by the facts that ours is a typical fifth-year credential program, with an emphasis on preparation for urban schools with many English learners, and that study participants taught in 18 middle and high schools across eight districts. In a few unavoidable cases, a participant was interviewed by a former instructor or supervisor; thus, participants may have steered their interview to please the researchers. An advantage of studying our own program was our insider knowledge of the program - the "input.” Rather than targeting an externally established list of "best" teaching practices, our list was generated to reflect the emphases of our courses and assessments. This strategy offered greater warrant to infer that 
observations of implementation of these Practices were indeed evidence of programmatic impact and a deeper understanding of program-related factors mentioned by participants.

\section{Theoretical Framework}

Explanations for mathematics teachers' limited uptake of university-emphasized practices have targeted the areas of teacher knowledge, teacher beliefs, and cultural environment. More specifically, prior scholarship has led teacher educators to question whether low implementation is the result of:

- the failure of a teacher-preparation model that teaches general pedagogical concepts prior to specific teaching methods

- the relative difficulty of reform-oriented mathematics teaching

- new teachers' struggle to bridge the "two worlds" of university and school

\section{The Concepts-First Teacher-Preparation Model}

Grossman, Smagorinski, and Valencia (1999) described teaching practice in terms of conceptual and practical tools:

Conceptual tools are principles, frameworks, and ideas about teaching [and] learning...that teachers use as heuristics to guide decisions.... Practical tools are classroom practices, strategies, and resources that do not serve as broad conceptions to guide an array of decisions but, instead, have more local and immediate utility. (p. 14)

Credential programs and professional development provide both kinds of tools; learning to teach involves actively adapting these tools for particular environments and consequently reconstructing and internalizing them. Various personal characteristics have been theorized to influence whether and how a teacher will appropriate a tool: One is knowledge, including mathematical knowledge (Ernest, 1989) and a grasp of the tool's conceptual underpinnings (Grossman et al., 1999). Another is the teacher's values and goals and their congruence with the culture promoting the tool (Grossman et al.). Teacher beliefs have also been presumed to influence tool uptake; these include the teacher's views on the nature of mathematics, the nature of mathematics teaching, and the process of learning mathematics (Ernest, 1989). Experience may also play a role. Grossman et al. posited that "mastery," the highest level of tool appropriation, in which teachers can generate and use practical instantiations of conceptual tools, may take years to achieve, long after the teacher has internalized the concepts. In mathematics teachers, Franke, Carpenter, Levi, and Fennema (2001) identified "generativity,” a desirable state similar to Grossman et al.’s “mastery”:

Generativity refers to individuals' abilities to continue to add to their understanding. When individuals learn with understanding, they can apply their knowledge to learn new topics and solve new and unfamiliar problems. When individuals do not learn with understanding, each new topic is learned as an isolated skill, and the skills they have learned can only be used to solve problems explicitly covered by instruction. (p. 655) 
Yet Franke et al. did not depict generativity as a developmental endpoint, leaving open the possibility that even new teachers, given the right training, could attain sufficient understanding to generate practical ideas from general concepts.

The limited uptake of university-promoted practices, then, may reflect the challenge of translating general conceptual tools learned at the university into specific classroom activities (Clift \& Brady, 2005). The Holy Grail for teacher educators is to deliver conceptual material in a way that engenders practice (Hiebert, Morris, \& Glass, 2003). Teacher educators assume that instilling in prospective teachers a strong foundational understanding of, and belief in, key pedagogical concepts will promote and is necessary for the teachers' use of associated methods in their classrooms. Indeed, the conventional structure of credential programs, with most coursework preceding the practicum, leaves little choice but to build concepts first. Some research, however, calls this assumption into question, suggesting that the natural order of teacher learning is from specific to general. Only through extensive experience with particular practical tools will teachers derive the general educational concept; teachers must do before they understand (Berliner, 1989). The standard teacher-preparation model may overestimate new teachers' ability to generate lesson ideas for particular teaching contexts, especially if veteran teachers must still develop this “mastery.” In Berliner’s (1989) view, credential programs should neither encourage teachers to design curriculum early in their careers nor discourage reliance on the textbook. Teacher preparation programs should emphasize practical tools and established teaching "scripts," saving conceptual tools for advanced professional development or postcredential graduate programs.

The question of order and proportion of conceptual versus practical tools in teacher education is highly relevant today. Some state and national policies in the U.S. limit the scope and length of university coursework and encourage streamlined alternative programs that reduce coursework in order to rush teachers into fulltime positions. A recent report by the National Council for Accreditation of Teacher Education (NCATE, 2010) advocates turning teacher education "upside down." Calling the current model "segmented with subject-matter preparation, theory, and pedagogy taught in isolated intervals and too far removed from clinical practice" (p. 2), NCATE recommends that field experiences run the duration of program and form its backbone, with coursework "woven around" and tightly integrated with fieldwork. NCATE envisions universities and K-12 districts and schools more evenly sharing responsibility for and authority over the design and evaluation of teacher education; some alternative programs cut universities out of the picture entirely. The erosion of universities' monopoly over teacher preparation behooves university faculty to confront the weak transfer of course-taught theory into everyday teaching and scrutinize the traditional model of theory first, then practice.

The relationship between beliefs and the appropriation of teaching tools is also debated. Beliefs about mathematics content, teaching, and learning were once considered a relatively static property of the teacher, preceding and directly shaping teaching practice, albeit filtered by contextual constraints. Reform-teaching practices were only expected to occur after traditional beliefs had been modified accordingly (Ernest, 1989). Research revealing inconsistencies between mathematics teachers' beliefs and practice or among an individual teacher's beliefs problematized this direct model (Hoyles, 1992). Cobb, Wood, and Yackel (1990) and Thompson (1992) contended that teachers' beliefs were constructed (or modified) in a dialectical relationship with practice, while Guskey (1986) suggested that teachers only changed their 
beliefs after changing their practice and seeing positive student outcomes. A related debate concerns the interactions of mathematics teachers' beliefs with the teaching context. Hoyles (1992) argued that beliefs were situated within the contexts, activities, and cultures in which the teacher constructed them and therefore differed across situations, thus explaining apparent inconsistencies. In contrast, Skott (2001) proposed that beliefs interacted with teaching contexts to produce situated actions, which responded to the teachers' changing motivations and goals; the beliefs themselves were relatively decontextualized and stable. Sztajn (2003) showed that teacher beliefs about particular students' social needs could override mathematical beliefs in shaping teaching. An uncertain relationship between beliefs and the uptake of teaching tools does not mean teacher-preparation programs should abandon the attempt to instill productive beliefs, but it suggests that doing so in the abstract, decontextualized environment of the university may have little effect on later practice. Further, it cautions against looking to beliefs to explain newteachers' limited use of university-taught tools.

\section{The Difficulty of Reform-Oriented Teaching}

Another explanation for the limited uptake of university-promoted methods is that, to the degree that they are reform oriented, they are more difficult to implement than traditional ones. Reform mathematics may make greater intellectual demands on teachers, including understanding mathematics content more deeply and flexibly (Borko et al., 1992; Lloyd \& Wilson, 1998), understanding the underlying pedagogical philosophy (Borasi \& Fonzi, 2002; Windschitl, 2002), and understanding students' mathematical thinking (Borasi \& Fonzi, 2002; Franke et al., 2001). New skills are also required: Teachers must continuously monitor and respond to students' thinking, design active learning tasks and environments, and cope with uncertainty (Windschitl, 2002). Cremin's diagnosis that the progressive reforms of the early $20^{\text {th }}$ century collapsed partly because they made "inordinate demands on the teacher's time and ability” (p. 348, 1961) may apply to mathematics reform today.

Further, reform-mathematics teaching may intensify the need to generate practical tools from conceptual ones. Prepackaged curricula and established delivery routines depreciate when teachers are expected to uncover and respond to students' learning needs during the lesson. Even when reform-oriented curricula and materials are available, as they increasingly are, if teachers lack the conceptual base, their implementation of these materials may be superficial (Windschitl, 2002). Simon and Tzur (1999) noted that mathematics teachers have appropriated certain reformoriented strategies (e.g., collaborative learning and the use of manipulatives) but the reform movement has not provided clear direction for how to help students develop mathematical ideas. Teachers may need years of sustained professional development (with technical, intellectual, and emotional support) to translate information from professional development into classroom practice (Lappan et al., 1988).

If reform practices were more difficult, they would seem especially prohibitive for new teachers. Alternately, veteran teachers, more deeply mired in tradition, might be more resistant to change. No large-scale studies differentiate mathematics teachers' reform implementation by experience level, but in a small-scale study, Remillard and Bryans (2004) found new teachers likelier than veterans to thoroughly implement and learn from reform-mathematics curriculum materials. Difficulty may explain the low implementation of reform practices, but research offers no reason to expect that it applies particularly to new teachers. 


\section{The “Two Worlds” Paradigm}

Sociocultural research perspectives have shifted our view of learning how to teach from an individual, cognitive phenomenon to a transformation in participation in a community of practice of educators (McLaughlin \& Talbert, 2001). The university and employing school are the major contexts for learning the culture and social organization of teaching (Borko et al., 1992). Moving from university to school is a process of re-enculturation: The new teacher must adjust to new goals and expectations and negotiate new roles within the school community (Stein \& Brown, 1997). This can feel like a transition between "two worlds" (Brown \& Borko, 1992). Universities train teachers in and evaluate them on a set of teaching practices that fundamentally differ from and sometimes clash with those teachers see and are evaluated on in the "real world" of schools. A central challenge for new teachers is straddling and reconciling these worlds (Clift \& Brady, 2005). Because teachers understandably prioritize the world of the employing school, the conflict shines an unfavorable light on the university, and teachers often devalue what they learn in university courses (Brown \& Borko, 1992; Shulman, 1998).

Stereotypically, the world of university mathematics-teacher preparation is characterized by reform-oriented practices, while the school world remains traditional. Lortie (1975) ascribed the failure of innovation to take hold in schools to three teacher "orientations": conservatism, individualism, and presentism. Conservatism is the inclination towards traditional methods and resistance to change. Especially when facing difficulties in the classroom, teachers fall back on the teaching model with which they are most familiar (Windschitl, 2002), in which, for most teachers, mathematics is fixed, linear, and best learned by memorization and solitary practice, and the teacher's role is to demonstrate and explain the procedures in the textbook and ratify the correctness of student work (Ball, 1990). Individualism includes teachers' desire for autonomy over their classrooms, distaste for interruption and scrutiny by colleagues and administrators, and the belief that personal experience is the principal route to growth. Presentism reflects teachers' short-term goal horizons and preference for quick-fix solutions to educational problems. These intertwined orientations are outgrowths of an occupational environment that offers unpredictable, sporadic rewards and no clear criteria for success. Arguably, this last condition has changed dramatically since 1975, with mathematics-teaching success explicitly defined today by students' standardized test scores. Yet Hargreaves and Shirley (2009) have noted that these orientations persist, despite recent reform-promoting initiatives. In particular the endemic presentism identified by Lortie has been augmented by adaptive presentism: a response to the current climate of high-stakes accountability and demand for rapid improvement (Hargreaves \& Shirley, 2009). Standardized testing may further suppress innovation if teachers perceive the tests to reward skill mastery and correct procedures and believe traditional teaching methods the most effective route towards these forms of learning (Windschitl, 2002).

Beyond their own orientations and their colleagues', teachers must contend with those of students, parents, and administrators, who typically posses traditional notions about education and mathematics. Teachers implementing reform pedagogies can find themselves having to "sell" their methods to resistant audiences, which can erode the motivation to reform (Windschitl, 2002). Even veteran teachers participating in reform-oriented professional development may be required to resolve the conflict between the professional-development community's understanding of good mathematics teaching and that of school authorities (Gresalfi \& Cobb, 2011). 
According to the two-worlds paradigm, the cumulative effect of these conditions is that new teachers' actions and attitudes evolve to match those of their veteran colleagues. The experiences of new teachers as students and the cultures of their employing schools push them to conform to the status quo and traditional modes of teaching. The ideas and practices endorsed by the university are overpowered by this press for tradition (Brown \& Borko, 1992; Grossman et al., 1999).

\section{Methods}

\section{Participants}

Improvements in the interview protocol between study years made the 2008 interview data more easily interpreted in terms of factors impacting the use of the Practices; thus, the reported findings come solely from 2008 interview data. All participants were graduates of Northridge's secondary-mathematics credential program, which is normally post-baccalaureate. Program applicants must demonstrate subject-matter competency through an undergraduate mathematics major or state examination; the program includes no mathematics courses per se. Student teaching occurs in the final two semesters, in a middle and high school, respectively. Besides the student-teaching seminars, only the one-semester methods course is mathematics specific.

Of the 52 graduates who earned the credential between Fall 2004 and Spring 2008, we were able to locate 36 who were employed as fulltime mathematics teachers; 19 were local and agreed to participate. These 19 participants were in their first through fourth year of teaching. Each was observed teaching one lesson and then interviewed. We were aware that more visits would have been required to characterize the practice of any individual teacher. We opted to use our limited resources for a broader look at our program, capturing as many graduates as possible, although this would only support a group analysis. We also expected this broader sample to offer a different view than that provided by case studies of a few teachers (e.g., Borko et al., 1992, Sztajn, 2003), as are more common. Despite having come from a single program, the participants taught in diverse settings. The 19 teachers taught in 18 public schools in eight districts. Six taught in middle schools and 13 in high schools. These urban and suburban schools ranged from 400 students to over 4000, with the percent of designated English Learners ranging from 3\% to $51 \%$ and the percent of students receiving Free or Reduced Lunch ranging from 1\% to 99\%.

\section{The Interview}

After each lesson observation, the researcher (or two researchers in early observations, to establish reliability) interviewed the teacher for about 45 minutes. Interviews were audiotaped and transcribed by the interviewer. Interview questions covered:

- the teachers' background;

- general ways in which the credential program and other experiences influence their practice today;

- general resources for and constraints on their teaching today;

- long-term career plans and expectations for professional growth; 
- (for third- and fourth-year teachers) how their teaching has changed since their first year and what accounts for this change.

Another set of questions was designed to address the Practices without sounding evaluative or implying that the researcher had hoped to see particular teaching actions. These took the forms:

- What things did you learn [asked separately for each source: at Northridge/in student teaching/from onsite mentors or professional development] that you find yourself using in your teaching?

- What things did you learn [repeat sources] that you wish you could use more in your teaching but find yourself unable? What prevents you?

- What things did you learn [repeat sources] that you find inappropriate or unhelpful in your current teaching situation? Why?

Another set took the forms:

- I saw you use [Practice (asked for each Practice observed)] in today's lesson. Why do you use this method? How frequently do you do this? Does it differ by class? Where did you learn how to do this? What challenges does it present? What resources support your use of this method? What constrains you from using this method more often?

- Do you ever use [Practice not observed]? [Repeat questions above.]

Because the literature questions whether beliefs about mathematics content, teaching, or learning can be validly measured in the abstract, and their relationship to practice is uncertain (Franke, Fennema, \& Carpenter, 1997; Hoyles, 1992), we did not directly attempt to determine participants' beliefs. We took the stance that teachers' actions are rational and coherent in their perspective and that our purpose should be to uncover that perspective (Philipp, 2007; Simon \& Tzur, 1999).

\section{Interview Analysis}

While a team of researchers conducted the observations and interviews, I was the primary analyst of the interview data. In my first reading of the transcripts, I listed every supporting and constraining factor any participant mentioned, whether for overall development, general teaching, the observed lesson, or a specific method. I then applied one of three codes to each factor:

- Direct: Explicitly linked by the teacher to one or more Practice (e.g., the teacher describes learning to teach with calculators at a workshop);

- Indirect: Probably or indirectly related to one or more Practice (e.g., the teacher reports "using many ideas" from a credential course);

- Unrelated: Either related to a non-Practice (e.g., learning an attendance-taking technique in student teaching) or ambiguous in direction of support (e.g., finding lesson ideas online).

I grouped these factors into categories, such as "onsite professional development" and "credential coursework." For each category, I tallied the number of teachers who mentioned one 
or more factors in it, separating Direct from Indirect references. This yielded a list of factor categories teachers perceived to support or constrain their use of the Practices, in order of salience to the group.

After charting these straightforward teacher citations of factors, I reread the interviews more holistically for themes that might provide additional explanation of what determined Practice adoption. One goal of this level of analysis was to provide detail, context, and meaning for the categories of factors that had emerged in the first pass. I sought to understand how and why these factors actually worked to encourage or discourage the Practices. Another goal was to unearth additional factors that participants had not made explicit. I was especially attentive to teacher comments related to the three explanations proposed in the literature: the difficulty of translating conceptual tools to practical ones, the difficulty of reform-mathematics teaching, and conflict between the university and school worlds. In the next section, I organize the presentation of my findings by these explanations, using tallies of factor categories and my interpretive analysis of the teachers' perceptions, along with illustrative quotes, to explore the validity of each explanation for this group of new teachers.

\section{Findings}

\section{Perceptions Related to a Concepts-First Teacher-Preparation Model}

The teachers in this study portrayed the credential program as the most significant factor promoting their use of the Practices. The student-teaching experience (including interactions with the master teacher or university supervisor) was the most frequently cited direct support for the Practices, followed by credential coursework. When indirect cites are included, equal numbers of teachers (14 out of 19) mentioned coursework and student teaching as sites for learning about or supporting their use of a Practice. Only one teacher saw an insufficiency in the credential program constraining the use of a Practice. Despite this support, implementation of the Practices was low, and further analysis of the interview data offers insight into the problems of translating Practices from credential program to classroom.

The strongest theme sounded by participants related to the distinction between conceptual and practical tools. These new teachers made clear that they learned from seeing and doing, with an emphasis on the latter. Their interviews revealed that they were strikingly literal: likeliest to implement a practice or activity when they had first at least observed, and ideally tried, in a classroom the specific instantiation of the Practice that they would implement. They lacked the confidence and/or ability to take a general idea (e.g., cognitive demand) from coursework or professional development and translate it into a usable plan for an actual lesson; they were far from "generative” (Franke et al., 2001). Even seeing a mentor or exemplary teacher use a method might not suffice; some participants felt the need to have tried it themselves in a guided setting before using it in their own classroom. As two of the teachers explained:

I could watch a teacher do all the things and copy what she does...but doing it and having her to guide me, that's the most important part.... I could, while I'm student teaching, remember stuff that I learned in my class and then apply it. But there's some kind of disconnect, because really they were never applied in those theoretical classes.... And 
that's hard to do without students and a classroom there, but we'd talk about what would you do in a situation like, "Little Sally does this; how would you help her?" But at the same time, that's still theoretical.... Somewhere along the line, I couldn't relate that to actually being in the classroom. (\#49; Year 1 Female)

With [university supervisor], he's all that discovery and inquiry, and it's hard to bring that into the curriculum because I haven’t done it consistently. So, even though he's encouraging it, like, "Try it this way! Inquiry, inquiry, discovery-based learning... You should do more of that!” But personally I wasn't really familiar with it, so it was hard to implement. (\#39; Year 2 Female)

Even trying the method in one setting might not help in the next. Some teachers struggled to translate a Practice from prior teaching if the current class had a different content focus. About a third of the teachers were constrained by not knowing how to use the Practices effectively with certain kinds of students. One teacher was stymied by a furniture configuration that differed from student teaching. As two teachers reported:

I really have a lot of trouble coming up with projects. I feel like I was taught stuff [at Northridge] about putting projects into math, but I can't remember specific ones, or ones that could relate to the class I'm teaching. Sometimes [Northridge] did it with algebra, and I'm teaching geometry and algebra $2 . .$. . My master teacher did a field trip, which I just thought was awesome, to have a math field trip. I just can’t think of one that I could use again for my class. That was a sixth-grade math class, and it was about compasses, and I’m not teaching that. (\#43; Year 2 Female)

[I saw an activity] about the relationship between shoe size and your head size-it's a scatterplot—and seeing the differences and understanding line of best fit, understanding regression lines. We did that, I remember, in student teaching. But I've never used it [here]. And that was an amazing activity! The students enjoyed being able to be tactile and just measure each other and laugh, just really have a good time doing math.... [Interviewer: So did this activity not fit your curriculum here?] No, I'm not doing [it] at all —In algebra 2 we do the data analysis, but algebra 1, we don't.... It's funny because I wanted so much to imitate both [master teachers], but because we taught a different curriculum [from what I use now], I think it was hard. (\#29; Year 4 Female)

Several teachers commented that an additional methods course or more student teaching would have been helpful; no teacher advocated for less of these. Our program does not require particular courses to be taken simultaneously with student teaching, but some teachers felt this would have enhanced their learning of the Practices:

I had to do pretty much all of my coursework before I started student teaching, and I just feel like all that coursework before was—not meaningless; like, it was important. But I didn't have anything to use it with. If I was student teaching while taking one of those classes, I can kind of relate it or use some of those skills. (\#43; Year 2 Female) 
While [the Foundations] class had a lot of good ideas, because I wasn't in a classroom yet, I wasn’t applying them right away and they kind of flew out of my brain. (\#51; Year 2 Female)

More time in methods courses would have equipped these teachers with more activities that could be directly imported into their classes, as some described doing.

When I'm planning lessons, I will think back. I'll be, like, OK, how did we do this? What did we do in [methods] class? And that methods class was, like, it really had a huge impact, because it was the first time I'd really been exposed to a lot of those things. I remember specific lessons that [classmates] taught. I teach lessons [today] that I designed for that class. (\#51; Year 2 Female)

Apparently, the benefit of more methods coursework would not have been learning additional practical tools (and certainly not additional conceptual tools) but experiencing a greater variety of specific instantiations of practical tools the teachers had learned, to increase the odds that those instantiations would match the context of their eventual teaching situation. Further, the extra "hands-on" teaching practice offered by extended or methods-course-concurrent student teaching would have built their confidence about using the Practices in their classrooms.

Related to literalness, a few teachers painted a picture of development that began with the literal imitation of the Practices or routines that mentors used. Two participants described learning from others:

When I started, I tried to mimic what [colleagues] were doing.... After that, I got the hang of it. So this year, for the first time, I'm able to just do it my way, my style, and being able to incorporate different concepts. Before, I was almost robotic. (\#29; Year 4 Female)

I teach almost exactly like my master teacher! I really liked his methods. When I was student teaching for him, I [decided] to stay with him all day. I was with him all six periods. I would observe him the two periods that I wasn't teaching.... It worked so well for him that I teach exactly the same way he did. (\#35; Year 2 Female)

Over time, these teachers felt themselves becoming more fluid and comfortable and developing their own style of implementation. Some expected the passage of time to enable them to implement the Practices:

One of my [master] teachers, she actually used group teaching. They sit in groups all the time, not just work for some particular task. And she had roles for every one of them assigned. But I cannot do it. I couldn't do it last year and I don't feel that I can do it this year. Maybe next year I will try. (\#36; Year 2 Female)

I haven't done much in a whole group, a group-of-four thing. I've done more of that in the curriculum with my master teacher because that was nontraditional. [Interviewer: Why not do it here?] I'm not ready yet. (\#45; Year 1 Male) 
The first semester my tables were not like this; they were just like they were in [master teacher's] class. And I tried to do a whole, “OK, you guys are working together; you're the Recorder, etc.” It just didn’t work. I wasn’t experienced enough to implement [groupwork]. (\#49; Year 1 Female)

The insistence on trying the Practices personally and the belief that time would bestow the ability to succeed with them-other developmental resources were rarely mentioned in this contextecho aspects of Lortie's individualism.

Professional development got mixed reviews, in particular for its contribution to the teachers' growing ability to use the Practices. Onsite professional-development activities were directly cited by five of the 19 teachers (and indirectly by two) as supporting one or more Practices. Teachers were sometimes offered general professional development (not mathematics specific) that aligned with the Practices, but they found this unhelpful - hard to translate to their particular settings and discipline.

At my school, a lot of the professional development that was brought in, like reciprocal teaching strategies, for example, most of the strategies that they provided did not apply to mathematics. Math is kind of a weird discipline, in that sense. A lot of strategies that work for more of the humanities, or courses where you're just kind of taking in information but not building skills, or not building skills that are built on the previous skills taught—all those strategies work, but they don't work as well in math.... My [school-assigned] mentor teacher was not a math teacher, so that was not particularly helpful. (\#8; Year 4 Female)

In sum, these teachers learned and valued practical tools in their early years and expected that continued growth would take the form of increasing accomplishment and comfort with the use of these tools, in more situations. They had difficulty generating practical tools from general concepts, although this was the expectation of their credential program and some onsite professional development.

\section{Perceptions Related to the Difficulty of Reform-Mathematics Teaching}

Many teachers complained about their inability to generate lesson ideas to incorporate Practices they know they should use and want to use. Seven of the 19 teachers directly (and one indirectly) cited their own limited knowledge or abilities as constraining Practice use. One teacher described the challenge of group activities:

When I was in high school, I worked out of [a reform] book - the integrated math. And so when I actually did my student teaching, I wasn't used to a textbook. I had never seen a math textbook! All my books were-I had a book, a math book, but the integrated math book is just, like, activities. Every class was groupwork. So when I started teaching, I wasn't used to seeing students in rows and teaching the whole period. Actually, it was kind of a culture shock to come into the classroom. So I keep trying to remember how 
those teachers did it... I did four years of groupwork in high school, and now it's like, why is it so hard for me to come up with groupwork activities? (\#35; Year 2 Female)

Others struggled to generate real-world connections:

That's one of those goals that I need to get to! It's one of those things that, you really want [students] to connect it, but sometimes I can't see the connection myself. Like, the last chapter in geometry was about chords and tangent lines and angles and circles. I mean, I really don't know an application of that. (\#43; Year 2 Female)

I feel like I need to do more of that. I haven't done much on that. In a way, I just want to have enough time to get through the lesson. Also, because I heavily rely on the textbook. There are a few examples in the book but, you know, there could be more. (\#45; Year 1 Male)

Another teacher wished she employed more active lessons, then noted:

I did have a lot of experience [at Northridge] planning lessons that were active and not just me lecturing, but it's kind of hard for me to come up with something like that. Maybe I have to teach the concept once and then figure out how am I going to-? Maybe next semester I could do that. But I always get stuck somewhere. (\#49; Year 1 Female)

The incorporation of the Practices into ready-to-use lessons in published resources would seem to increase the odds of their use. When asked about the resources they drew on for lesson plans, these participants echoed many:

The book is the main source, and then the book has auxiliary materials that you can use as well. The new books...have a lot of electronic media now. When we examined the new ones - the texts are online - they have better test generators, better review sessions already scripted, and all this stuff is on CD and/or websites. I expect to use them more when we adopt the new books. (\#16; Year 4 Male)

Usually, I will look to see what the resources I have are. And if I don't like them, I always go online and I research. And I say, OK, what has someone else done? Do I like that? And I tend to modify, and then I come up with my own activity. So what I tend to do - my personality is I go through and see what everyone else did, and then I tweak it, from my angle. (\#24; Year 3 Female)

Four of the 19 teachers directly mentioned using online resources to support a Practice. Lesscited supports were published materials beyond the course textbook and observing colleagues. Six teachers blamed a lack of resources for constraining their use of a Practice.

The inability to generate Practice-based lessons may be a matter of limited creativity or knowledge, but two other factors evidently contribute: a fear of the lesson going poorly, and time. Our graduates felt pressure (whether self- or administration-imposed was unclear) to have lessons work the first time, where "work" meant the material got covered and the class remained 
under control. Remarkably, only one teacher described anything sounding like experimentation. More felt as this teacher did:

I wish I could do more creative activities besides what's done in the book.... I think of the fear that they're not gonna get it. It's a time factor, that they're not gonna get it in the time that I’ve allotted. So lack of patience. Yeah, I think it’s fear. (\#29; Year 4 Female)

Time was the omnipresent constraint - the most frequently cited constraint on the Practices. Eleven of the 19 teachers directly (and one indirectly) cited limited class time as an obstacle, perceiving the Practices to take longer than direct instruction. Nine directly (and two indirectly) blamed a lack of time to plan Practice-based lessons, find Practice-related resources or technologies, or learn how to use them. As these new teachers described their hectic jobs and lives, it became evident that there was little room for lesson planning. This may help explain why asking high-level questions and giving students autonomy were the most used Practices: They can be accomplished (though perhaps not well) with little advance planning and incorporated fairly easily into a direct-instruction lesson lifted from a textbook. Other Practices may require the teacher to do more planning or research or learn a new technology-activities that take time our graduates may not have or that are of low priority if no school personnel encourage their use.

Surprisingly, these teachers did not cite standardized tests as a direct constraint on the Practices. Yet the main constraint-limited class time-is arguably a close derivative. Most participants were required to follow curricular guides, keyed to the content of state and district tests, that forced a rapid pace through the textbook. This sort of pressure may be more intense in mathematics, a heavily tested subject. The other difficulties described in this section, however, may be common to new teachers across subjects.

\section{Perceptions Related to the "Two-Worlds" Paradigm}

Many teachers reported a high level of collegial support, though not necessarily for the Practices per se, and they relied on colleagues for informal teaching ideas and advice:

We meet every week [in course teams], and sometimes we discuss what we're doing in class and maybe some ideas of how people are doing different things. So that's really helpful. Also, sometimes people share their handouts.... Because I have the hang of it now, I think it's easier to teach algebra 1. But before, I would rely heavily upon other teachers, when I was just starting off. I would be in their rooms all the time, asking, "What are you doing? Can I get a copy?”, checking out their websites. (\#29; Year 4 Female)

[Interviewer: What have you got here to support your teaching?] Everything! [My former mentor] down the road; my department chair is always willing; the principal told me that, you know, open-door policy. Even people on campus that know me and I have no idea who they are, they're like, "Oh, how ya doing? You doing OK? Do you need anything?” ... [Course teams] have meetings biweekly. So if there's any questions or when it's time to make a new test, we're always talking about it. And through email, I can always ask anyone a question, and by the end of the day there'll be an answer. [Interviewer: Do you 
work closely together on the same curriculum?] We work closely together for [pause] help. The math department doesn't really work together in terms of curriculum. Like, for algebra 2, they told me, "You're on your own in terms of pacing and everything." And I'm like, "I've never taught algebra 2! How do I know if Section 1.6 is gonna be one or two days? I have no clue!” (\#13; Year 4 Female)

These sentiments may seem in conflict with conventional portrayals of teaching as isolated and private. Yet they align with the individualistic orientation described by Lortie (1975) and Little (1988): Teachers value help, ideas, and resources from colleagues, but only when these things are solicited and optional and do not threaten teachers' reputedly equitable status. The contrast may come in the area of formal collaborative structures for the purpose of departmental or school-wide instructional improvements, which held little interest for the teacher of 1975 (Lortie). Many of the teachers in this study were involved in formal learning communities or had notably collaborative departments. In the more collaborative settings, a "When in Rome..." rule seemed to apply. A school or department where colleagues used the Practices and where formal collaborative arrangements and professional development supported the Practices did appear to encourage new teachers to adopt the Practices-made it likelier that a teacher who had learned about the Practices at the university and wanted to implement them actually would. One teacher praised a voluntary professional-development initiative ("PDI") that convened mathematics teachers eight times a year:

[PDI] covers points like questioning techniques and how to address EL learners. Yesterday, we were watching a videotape of a teacher in a classroom with the questioning, which I tried to remember [today] when I was questioning. And they actually pound that in: Try not to give away too much answers. Try to ask higher-order thinking questions. Don't dumb down everything. Have higher expectations. So I try to remember those things. Those have great impact. (\#23; Year 4 Female)

Another teacher teamed up with a more experienced Northridge alumnus at his school:

I get a lot of ideas from him. I can’t run my class the same way he does. He does group activities every day. He has pods. I can't do that; I'm not that organized. 'Cause he's on top of it. But I do get a lot of activities from him as well, that I just kind of modified. (\#47; Year 1 Male)

Another credited her department chair for encouraging the Practices:

I really like teaching in this school, because our department chair is really into different ways of teaching and doing stuff that's not very traditional.... She does amazing things in her classroom. So the fact that she's steering our ship really gives me a lot of freedom to do stuff that I don't think I would necessarily —not be able to do, but the fact that when I do it, it’s, like, “Oh, cool!” And people are OK with it. (\#51; Year 2 Female)

While collaboration in the "school worlds" of these teachers may not have directly supported the Practices, there were few reports of cultural constraints on the Practices. Three teachers taught in schools with complete or partial bans on student calculator use. All other 
cultural complaints were indirect: Two teachers described departmental disagreement about curricular issues but did not explicitly link this to Practice implementation; one cited the required text and another cited departmental assessments as constraints on teaching but, again, not necessarily on any Practice.

\section{Discussion}

\section{Is the Standard Teacher-Preparation Model to Blame?}

The literalism that emerged - the teachers' discomfort with using a method that they had not practiced to the point of competence in a similar classroom context, and their professed inability to translate general pedagogical ideas into specific plans-underscores Grossman et al.'s (1999) distinction between conceptual and practical tools. One framing of this study's findings is that these new teachers learned certain practical tools in the credential program and were willing and able to use them relatively directly. They also learned, perhaps even internalized, conceptual tools, but at this early point in their career were unable to generate practical tools that capitalize on these concepts. Professional-development activities designed to impart conceptual tools felt useful to these teachers to the degree that they supplied practical tools for immediate use. Similarly, despite their reputation as concept heavy and impractical, university courses were often valued by these teachers for the practical tools they offered (e.g., specific lesson plans), even when the instructors had intended these practical tools only to illustrate concepts (Borko et al., 1992). These findings align with a teacher-learning trajectory that begins with the mastery of specific practical tools and routines, from which teachers gradually construct an understanding of broad educational concepts and the ability to use them to generate instructional plans for a range of contexts. Perhaps all professionals need extensive experience with practical tools before they truly grasp the associated concepts or theories in a generative way. Consider that engineering students first learn to imitate established mathematical procedures and only gradually take on open-ended design or modeling problems, even though the fundamental concepts of their profession are also taught from Day One.

How this trajectory unfolds over a career is uncertain. Difficulty generating specific teaching activities from general conceptual tools is apparently not limited to new teachers. Mitchell (1950) observed experienced teachers in a workshop literally and inappropriately replicating in their classrooms the workshop activities as presented, rather than adapting them to their teaching situations. This raises the question of whether teachers, over time, develop the ability to generate specific teaching ideas from broader concepts, as Grossman et al. (1999) posited, or whether this task challenges teachers throughout their career. And if experience enhances this ability, does overall experience suffice, or must the experience expressly increase familiarity with the specific conceptual tool? Perhaps Mitchell's veteran teachers struggled to move from general to specific because the particular conceptual tool was new to them. If so, it would suggest that, in some sense, teachers become "beginners" again when learning a new conceptual tool, and that familiarity with a conceptual tool would better predict a teacher's ability and willingness to generate corresponding practical tools than would years of experience (paralleling Borko and Livingston's [1989] finding that expert mathematics teachers become more like novices when teaching new mathematical content). Teacher development might then be considered a set of jumps in expertise, as conceptual tools are focused on and learned, one by 
one. Alternately, it may be experience in a specific teaching context that enables teachers to generate practical tools from conceptual ones. Berliner (1992) demonstrated the context specificity of expertise when the veteran teachers he studied lost their "edge" and composure when asked to teach in or analyze unfamiliar classroom settings, bereft of their usual knowledge about the students and material. A third possibility is that experience discourages teachers from translating concepts into practice, as time served in schools exacerbates presentism. The unceasing pressure for immediate improvements might erode teachers' willingness to generate lesson ideas from broad, theoretical notions about learning, even as they become abler to do so.

Whether and how experience impacts teachers' ability or disposition to move from the general/conceptual to specific/practical are important questions for future research, with significant implications for career-span teacher education. Regardless, while this study does not challenge the value of teaching general concepts to prospective teachers, it shows that without significant accompanying practical training, their ability to capitalize on those concepts is severely constrained.

\section{Is the Difficulty of Reform to Blame?}

The idea that teacher development moves from the specific and practical to the general and conceptual offers insight into the idea that reform-mathematics teaching is more difficult and, hence, rarer than traditional teaching. The reform-oriented methods promoted in universities may fundamentally differ from traditional practices in that the latter can be carried out by following scripts, textbooks, and other widely available resources, while the former require some degree of teacher generation and adaptation. If so, we should temper our expectations about the extent to which new mathematics teachers can master reform teaching but ramp up such expectations for midcareer professional development. Alternately, reform and traditional mathematics teaching may not be inherently different in terms of what teachers must generate but be de facto different in this respect because far more resources, scripts, and routines are currently available for traditional methods, due to their longer history and ubiquity.

This study did not compare the difficulty of traditional and reform teaching, but it shows that materials at hand and local efforts to institutionalize reform practices facilitate their uptake by new teachers. Thus, the argument that reform-oriented teaching is more challenging may be unnecessary to explain its rarity. If reform-oriented teaching could be learned by following routines and scripts, if teachers were provided such things, and if colleagues modeled reform methods daily (as they now do traditional methods), we would likely see more reform teaching across the career spectrum. Teacher conservatism may not reflect a propensity towards traditional methods per se as much as towards the known, popular, and readily at hand. Recall the participant who had experienced reform mathematics as a high-school student: Now, as a teacher, her "apprenticeship of observation" of reform teaching has been overpowered by the immediate availability of traditional materials and routines. Of course, ubiquity would not guarantee that reform materials and scripts would be used with fidelity to their underlying theories. Yet if teachers must construct pedagogical concepts from practical experience, ubiquitous reform materials and scripts would go a long way towards helping teachers build solid understandings of reform's philosophical underpinnings. Ideal for future research on this issue would be a school saturated with reform materials and teachers who model reform teaching, 
where new teachers' uptake of reform methods could be compared with their counterparts' uptake of traditional methods in traditional settings.

\section{Are “Two Worlds" to Blame?}

The finding that the most consistently cited support for adopting the Practices was learning about them in the credential program is heartening for universities. The comments of these teachers suggest that they graduated with a strong foundational knowledge of the Practices, the belief that these Practices represent good teaching, and the desire to employ at least some of them. Very few participants depicted any aspect of the credential program as useless or inappropriate for their current teaching, and several have returned to us for masters degrees. (Of course, participants may have wanted to paint a rosy picture of their credential program. It would have been informative to hear their responses to interviewers unconnected to Northridge.) A few complained that their master teachers had not demonstrated enough variety of methods, and many indicated that few current colleagues modeled methods they had learned in our program. But almost no teacher gave the impression that, by implementing the Practices today, she would be violating school norms or negatively perceived by colleagues or administrators. Many worked in schools that, at least rhetorically, encouraged the Practices through onsite professional development. And many were taking small steps towards implementing one or more Practices.

Thus, for these teachers, low Practice implementation does not appear to be the result of leaving one world behind, unlearning what was taught there, and struggling to learn the contradictory ways of a foreign culture. Nevertheless, the teaching environment strongly determines whether the new teacher will continue along the developmental trajectory initiated in the credential program, gradually mastering the Practices, or whether this development will be extinguished.

\section{Programmatic Implications}

The findings of this study suggest that the route to regular implementation of universitypromoted mathematics-teaching practices requires neither complicated nor revolutionary changes to teacher education. Both university and employing school play crucial roles, and changes in both arenas would facilitate the uptake of such practices, but paradigm shifts may not be required. Credential programs can build a strong and necessary foundation for teaching, but this foundation is insufficient for most graduates to implement the Practices in the field. The sentiments of this study's participants imply that programs should structure in more opportunities to use these Practices. Student teaching and in-class microteaching are critical: New teachers need to have rehearsed a method almost to the point of habit before they will use it in their classrooms (Guskey, 1986). Kazemi, Franke, and Lampert's (2009) use of “public guided rehearsals" of instructional activities in credential courses seems a near perfect prescription for the teachers in this study.

Credential programs strive to place student teachers with master teachers who align philosophically with the program, but programs rarely ensure that student teaching involves specific practices. One way to accomplish this would be to make formal student-teacher evaluation reflect subject-specific methods. The student-teacher evaluation form could provide 
master teachers and supervisors with a list of practices that they must find opportunities for the student teacher to experience. Also, credential-course instructors should ensure that the general ideas and approaches discussed are regularly translated, by instructors or students, into specific activities for specific types of classes. Programs like ours, serving a largely nontraditional, parttime student population, must offer flexible course sequencing and may be reluctant to mandate that student teaching coincide with the methods course. But informal field experiences could be built into the methods course so that practices discussed in the course could be observed or tried and analyzed in real classrooms. Less ideally, teacher demonstrations of desirable methods could be viewed by video (Hatfield \& Bitter, 1994). Future research should investigate how providing prospective mathematics teachers with more structured opportunities to practice reform methods impacts their eventual teaching behavior.

A key determinant of implementation is the conduciveness of the employing school's culture to the Practices. Research linking teacher-learning communities to improved teaching and reform (Franke et al., 2001; Gresalfi \& Cobb, 2011; McLaughlin \& Talbert, 2001; Stein \& Brown, 1997) apparently holds for new teachers: Ongoing professional development that builds a community for a Practice and that resonates with the wider school culture appears to promote implementation. At least for new teachers, this professional development encourages implementation even more so when it provides concrete activity plans for their particular classrooms. Many schools have created small learning communities of teachers and students, and some have adapted Japanese Lesson Study. To the degree that these efforts focus on the Practices and how to implement them effectively with the school's students, they represent significant school-level contributions to the growth of teachers who make these Practices central to their teaching. University faculty time would be well spent partnering with area schools to support onsite development efforts that enculturate the Practices, and studying the impact of this partnership.

Acknowledgement: I thank Marian Pasternack for her research assistance, and Megan Staples and David Miller for editorial help. This study was funded by a Teachers for a New Era grant from the Carnegie Corporation of New York, Ford Foundation, and Annenberg Foundation. 


\section{References}

Ball, D. L. (1990). Breaking with experience in learning to teach mathematics: The role of a preservice methods course. For the Learning of Mathematics, 10(2), 10-16.

Berliner, D. C. (1992). The nature of expertise in teaching. In F. K. Oser, A. Dick, \& J-L. Patry (Eds.), Effective and responsible teaching: The new synthesis (pp. 227-248). San Francisco: Jossey-Bass.

Berliner, D. C. (1989). Implications of studies of expertise in pedagogy for teacher education and evaluation. In Proceedings of the 1988 Educational Testing Service Invitational Conference, New Directions for Teacher Assessment (pp. 39-65). Princeton, NJ: Educational Testing Service.

Borasi, R., \& Fonzi, J. (2002). Foundations (vol. 3): Professional development that supports school mathematics reform. Arlington, VA: National Science Foundation.

Borko, H., \& Livingston, C. (1989). Cognition and improvisation: Differences in mathematics instruction by expert and novice teachers. American Educational Research Journal, 26(4), 473-498.

Borko, H., Eisenhart, M., Brown, C. A., Underhill, R. G., Jones, D., \& Agard, P. C. (1992). Learning to teach hard mathematics: Do novice teachers and their instructors give up too easily? Journal for Research in Mathematics Education, 23(3), 194-222.

Brown, C. A., \& Borko, H. (1992). Becoming a mathematics teacher. In D. A. Grouws (Ed.), Handbook of research on mathematics teaching and learning (pp. 209-239). New York: Macmillan Publishing Company.

Clift, R. T., \& Brady, P. (2005). Research on methods courses and field experiences. In M. Cochran-Smith, \& K. M. Zeichner (Eds.), Studying teacher education: The report of the AERA panel on research and teacher education (pp. 309-424). Mahwah, NJ: Lawrence Erlbaum.

Cobb, P., Wood, T., \& Yackel, E. (1990). Classrooms as learning environments for teachers and researchers. In R. B. Davis, C. A. Maher, \& N. Noddings (Eds.), Journal for Research in Mathematics Education: Constructivist views on the teaching and learning of mathematics (Monograph No. 4, 125-146). Reston, VA: National Council of Teachers of Mathematics.

Cremin, L. A. (1961). The transformation of the school: Progressivism in American education, 1876-1957. New York: Alfred A. Knopf.

Ernest, P. (1989). The impact of beliefs on the teaching of mathematics. Retrieved from: http://people.exeter.ac.uk/PErnest/impact.htm on June 24, 2011. 
Franke, M. L., Carpenter, T. P., Levi, L., \& Fennema, E. (2001). Capturing teachers' generative change: A follow-up study of professional development in mathematics. American Educational Research Journal, 38(3), 653-689.

Franke, M. L., Fennema, E., \& Carpenter, T. (1997). Teachers creating change: Examining evolving beliefs and classroom practice. In E. Fennema, \& B. S. Nelson (Eds.), Mathematics teachers in transition (pp. 255-282). Mahwah, NJ: Lawrence Erlbaum.

Gresalfi, M. S., \& Cobb, P. (2011). Negotiating identities for mathematics teaching in the context of professional development. Journal for Research in Mathematics Education, 42(3), 270-304.

Grossman, P., Compton, C., Igra, D., Ronfeldt, M., Shahan, E., \& Williamson, P. (2009). Teaching practice: A cross-professional perspective. Teachers College Record, p. 20552100. Retrieved from http://www.tcrecord.org ID Number: 15018, May 27, 2011.

Grossman, P. L., Smagorinski, P., \& Valencia, S. W. (1999). Appropriating tools for teaching English: A theoretical framework for research on learning to teach. American Journal of Education, 108, 1-29.

Guskey, T. R. (1986). Staff development and the process of teacher change. Educational Researcher, 15(5), 5-12.

Hargreaves, A., \& Shirley, D. (2009). The persistence of presentism. Teachers College Record, 111(11) Retrieved from http://www.tcrecord.org ID Number: 15438, June 62009.

Hatfield, M. M., Bitter, G. G. (1994). A multimedia approach to the professional development of teachers: A virtual classroom. In D. B. Aichele (Ed.), NCTM 1994 Yearbook:

Professional development for teachers of mathematics (pp. 102-115). Reston, VA:

National Council of Teachers of Mathematics.

Hiebert, J., Morris, A. K., \& Glass, B. (2003). Learning to learn to teach: An "experiment” model for teaching and teacher preparation in mathematics. Journal of Mathematics Teacher Education, 6, 201-222.

Hoyles, C. (1992). Mathematics teaching and mathematics teachers: A meta-case study. For the Learning of Mathematics, 12(3), 32-44.

Jacobs, J., Hiebert, J., Givvin, K., Hollingsworth, H., Garnier, H., \& Wearne, D. (2006). Does eighth-grade mathematics teaching in the United States align with the NCTM Standards? Results from the TIMSS 1999 video studies. Journal for Research in Mathematics Education, 37(1), 5-32.

Kazemi, E., Franke, M., \& Lampert, M. (2009, July). Developing pedagogies in teacher education to support novice teacher's ability to enact ambitious instruction. Keynote Address to the $32^{\text {nd }}$ Annual Conference of the Mathematics Education Research Group of 
Australasia, New Zealand. Retrieved October 7, 2011from

http://www.merga.net.au/documents/Kazemi.pdf.

Lappan, G., Fitzgerald, W., Phillips, E., Winter, M. J., Lanier, P., Madsen-Nason, A., et al. (1988). The middle grades mathematics project: The challenge: Good mathematicstaught well. Final report to the National Science Foundation for grant no. MDR8318218. East Landing, MI: Michigan State University.

Little, J. W. (1988). Assessing the prospects for teacher leadership. In A. Lieberman (Ed.), Building a professional culture in schools (pp. 78-106). New York: Teachers College Press.

Lortie, D. C. (1975). Schoolteacher: A sociological study. Chicago: University of Chicago Press.

Lloyd, G. M., \& Wilson, M. (1998). Supporting innovation: The impact of a teacher's conceptions of functions on his implementation of a reform curriculum. Journal for Research in Mathematics Education, 29(3), 248-274.

McLaughlin, M., \& Talbert, J. (2001). Professional communities and the work of high-school teaching. Chicago: University of Chicago Press.

Mitchell, L. S. (1950). Our children and our schools. New York: Simon and Schuster.

National Council for Accreditation of Teacher Education (NCATE). (2010). Transforming teacher education through clinical practice: A national strategy to prepare effective teachers. Retrieved from http://ncate.org. on November 18, 2010.

National Council of Teachers of Mathematics (NCTM). (1989). Curriculum and evaluation standards for school mathematics. Reston, VA: NCTM.

National Council of Teachers of Mathematics (NCTM). (1991). Professional standards for teaching mathematics. Reston, VA: NCTM.

National Council of Teachers of Mathematics (NCTM). (2000). Principles and standards for school mathematics. Reston, VA: NCTM.

Philipp, R. A. (2007). Mathematics teachers' beliefs and affect. In F. K. Lester, Jr. (Ed.), Second handbook of research of mathematics teaching and learning (pp. 257-315). Charlotte, NC: Information Age Publishing.

Remillard, J. T., \& Bryans, M. B. (2004). Teachers’ orientations toward mathematics curriculum materials: Implications for teacher learning. Journal for Research in Mathematics Education, 35(5), 352-388.

Shulman, L. (1998). Theory, practice, and the education of professionals. The Elementary School Journal, 98(5), 511-526. 
Simon, M. A., \& Tzur, R. (1999). Explicating the teacher's perspective from the researchers' perspectives: Generating accounts of mathematics teachers’ practice. Journal for Research in Mathematics Education, 30(3), 252-264.

Skott, J. (2001). The emerging practices of a novice teacher: The roles of his school mathematics images. Journal of Mathematics Teacher Education, 4, 3-28.

Stein, M. K., \& Brown, C. A. (1997). Teacher learning in a social context: Integrating collaborative and institutional processes with the study of teacher change. In E. Fennema, \& B. S. Nelson (Eds.), Mathematics teachers in transition (pp. 155-191). Mahwah, NJ: Lawrence Erlbaum.

Sztajn, P. (2003). Adapting reform ideas in different mathematics classrooms: Beliefs beyond mathematics. Journal of Mathematics Teacher Education, 6, 53-75.

Thompson, A. G. (1992). Teachers' beliefs and conceptions: A synthesis of the research. In D. A. Grouws (Ed.), Handbook of research on mathematics teaching and learning (pp. 127146). New York: Macmillan Publishing Company.

Windschitl, M. (2002). Framing constructivism in practice as the negotiation of dilemmas: An analysis of the conceptual, pedagogical, cultural, and political challenges facing teachers. Review of Educational Research, 72(2), 131-175. 